\title{
ADDITION OF DEXAMETHASONE INJECTION TO PREEMPTIVE ORAL PREGABALIN DOES NOT IMPROVE POSTOPERATIVE ANALGESIA OVER PREGABALIN ALONE FOR ABDOMINAL HYSTERECTOMY UNDER GENERAL ANAESTHESIA
}

\author{
${ }^{1}$ Assistant Professor, Department of Anaesthesiology, North Bengal Medical College. \\ ${ }^{2}$ Assistant Professor, Department of Anaesthesiology, North Bengal Medical College. \\ ${ }_{3}^{3}$ Associate Professor, Department of Anaesthesiology, North Bengal Medical College. \\ ${ }_{4}^{4}$ Associate Professor, Department of Anaesthesiology, North Bengal Medical College. \\ 5Professor, Department of Anaesthesiology, North Bengal Medical College.
}

Santanu Ghosh', Subhrajyoti Chattopadhyay2, Susanta Sarkar ${ }^{3}$, Mohanchandra Mandal', Sekhar Ranjan Basu ${ }^{5}$

\section{ABSTRACT}

\section{BACKGROUND}

Effective control of postoperative pain reduces nociception-induced responses and morbidity in the postoperative period. The aim of this study is to evaluate whether the prophylactic use of pregabalin $300 \mathrm{mg}$ along with dexamethasone $8 \mathrm{mg}$ and paracetamol $1000 \mathrm{mg}$ improves analgesia after abdominal hysterectomy operation.

\section{METHODOLOGY}

All the participants were randomly allocated to receive either oral pregabalin + injection dexamethasone (group-A, $\mathrm{n}=25$ ) or pregabalin + placebo injection (Group-B, $n=25$ ) or placebo capsules and placebo injection (Group-C, $n=25$ ) 1 hr before surgery.

General anaesthesia with endotracheal intubation was provided for surgery and subsequently reversed following a standard protocol. After surgery patients were monitored for the next 24 hours in the recovery room where they received $1000 \mathrm{mg}$ of paracetamol 8 hourly. Episodes of pain were treated with intravenous fentanyl $25 \mathrm{mcg}$ (rescue analgesic) at 10 minutes interval until pain subsides or any complication started or maximum allowable dose $(100 \mathrm{mcg} / \mathrm{hr}$.) exceeds. The patients were assessed postoperatively at 1, 4 and 24 hours. The intensity of pain was assessed using visual analogue scale at rest and with movement. Levels of postoperative nausea, vomiting, sedation and any occurrence of headache and light-headedness were recorded during this period.

\section{RESULTS}

A significant reduction of fentanyl consumption (33\%) was observed in the first 24 postoperative hours with single dose of 300 mg pregabalin. Reduced VAS scores (in $\mathrm{mm}$ ) were observed in patients receiving pregabalin+dexamethasone combination or pregabalin alone compared with placebo at 1 st hour [ $18.81 \pm 5.89$ vs. $22.86 \pm 9.94$ vs. $42.95 \pm 9.21]$; at 4 th hour $[8.81 \pm 3.12$ vs. $8.81 \pm 4.44$ vs. $26.36 \pm 8.05$ ] and at 24 th hours [ $9.05 \pm 3.75$ vs. $8.10 \pm 4.02$ vs. $15.00 \pm 5.35$ ] of postoperative period [group-wise data represented respectively]. Sedation remained the most significant adverse effect among patients receiving pregabalin.

\section{CONCLUSION}

Addition of single dose injection dexamethasone $8 \mathrm{mg}$ has no discernible effect on postoperative analgesia achieved with preemptive oral pregabalin except some alleviation of postoperative nausea and vomiting.

\section{KEYWORDS}

Multimodal Analgesia, Pregabalin, Dexamethasone, Paracetamol, Postoperative Pain, Abdominal Hysterectomy.

HOW TO CITE THIS ARTICLE: Ghosh S, Chattopadhyay S, Sarkar S, et al. Addition of dexamethasone injection to pre-emptive oral pregabalin does not improve postoperative analgesia over pregabalin alone for abdominal hysterectomy under general anaesthesia. J. Evolution Med. Dent. Sci. 2016;5(53):3544-3548, DOI: 10.14260/jemds/2016/817

\section{INTRODUCTION}

Reduction of nociceptive input into Central Nervous System (CNS) and optimisation of postoperative analgesia may decrease complications and facilitate the patients' recovery from surgical stress. ${ }^{1}$ Multimodal postoperative analgesia is based on combination of opioids, nonsteroidal antiinflammatory drugs (NSAIDs), or paracetamol along with local

Financial or Other, Competing Interest: None.

Submission 29-04-2016, Peer Review 15-06-2016,

Acceptance 21-06-2016, Published 04-07-2016.

Corresponding Author:

Dr. Subhrajyoti Chattopadhyay,

C/o. Mr. Satyajit Chakroborty,

Trinayani Apartment (2nd Floor),

Taltala, Arabinda Pally,

Siliguri-734006,

West Bengal.

E-mail: drsubhra1972@gmail.com

DOI: $10.14260 /$ jemds $/ 2016 / 817$ anaesthetics that facilitates early discharge and reduces health care burden. ${ }^{2}$

Pregabalin, an antiepileptic drug, used extensively for neuropathic pain, has analgesic properties, opioid-sparing effects, and anxiolytic action. Pregabalin blocks hypersensitivity to pain in the postoperative period thus reducing postoperative pain as well as opioid consumption. ${ }^{3}$ Paracetamol and NSAIDs are effective ways of reducing postoperative pain. Addition of glucocorticoids has been shown to further decrease the postoperative pain and thereby opioid consumption. ${ }^{4}$ We hypothesised that preoperative use of pregabalin and dexamethasone would reduce postoperative pain thereby would reduce opioid consumption and opioidrelated adverse effects after abdominal hysterectomy.

\section{AIMS AND OBJECTIVE}

The aim of this study was to evaluate whether the prophylactic use of pregabalin along with dexamethasone and paracetamol 
would improve analgesia after abdominal hysterectomy. The objective of the study was to evaluate the effect of preoperative pregabalin in terms of analgesic requirement in the first 24 hours postoperative period (Primary outcome). Secondary outcomes were Visual analogue Scale (VAS) scores, both static and dynamic (using 0 to $100 \mathrm{~mm}$ scale) at 1, 4, 24 hours postoperatively and adverse events, if any.

\section{Study Population}

Female patients aged between 35 to 70 years, of ASA physical status I or II, posted for elective abdominal hysterectomy were assessed for eligibility based on predefined exclusion criteria.

\section{Exclusion Criteria}

Patients with communication problem, history of hypersensitivity to any drugs in the study, with impaired respiratory function, uncontrolled chronic systemic disease such as diabetes, hypertension, collagen vascular disorder, and liver disorders or history of chronic analgesic, sedative, and steroid intake.

\section{Study Techniques}

At first, permission from Institutional Ethics Committee was obtained. Written informed consents were taken from all participants at pre-anaesthetic checkup after proper explanation of the study procedure in their own language. After admission in the hospital, each patient was visited and again explained about the use of visual analogue scale.

\section{Sample Size}

Sample size was calculated using analgesic efficacy as the main criterion. Preoperative use of pregabalin has been seen to decrease the requirement of postoperative analgesic supplements by $50 \%$ [study group $24 \pm 14 \mathrm{mcg}$; control group $47 \pm 28 \mathrm{mcg}] .{ }^{[5]}$ We assumed that addition of pregabalin would decrease the requirement of rescue analgesic (Fentanyl) by 25 mcg in the study groups compared to the other group not receiving pregabalin. Considering the alpha value of 0.05 and power of study (1- $\beta$ ) at $80 \%$, a minimum sample size of 20 patients was necessary for each group. Expecting some dropout, a total of 75 patients were recruited; 25 in each group. $P$ value $<0.05$ was considered significant.

Randomisation and Blinding: Capsules identical to pregabalin $300 \mathrm{mg}$ containing placebo were prepared by the Pharmacology Department. Identical syringes containing either dexamethasone $8 \mathrm{mg}$ or $2 \mathrm{~mL}$ of isotonic saline prepared by a nurse who did not take part into the study any further. Study medications were packed into separate container having consecutive number according to the computer generated block randomisation. Each block contained 15 numbers, which nearly corresponds to the eligible patients posted for abdominal hysterectomy in each fortnight. The patients were assigned consecutively to their group according to their number. Thus, all the participants were randomly allocated to receive either oral pregabalin + injection dexamethasone (Group-A), pregabalin + placebo injection (Group-B), or placebo capsules and placebo injection (GroupC). Both the patient and the observer were blind to these group allocations.

\section{Intervention Proper}

Tablet diazepam $5 \mathrm{mg}$ and tablet ranitidine $300 \mathrm{mg}$ were given at the night before surgery. Tablet paracetamol $1000 \mathrm{mg}$ was given orally two hours before surgery. They received either pregabalin or placebo capsules with intravenous injection of dexamethasone or placebo 1 hour before operation according to randomisation assignment. On arrival in the operating room, the baseline vital parameters of the patients were recorded. After preoxygenation induction of anaesthesia was done with intravenous injection of propofol 1.5-2.5 mg/kg, vecuronium $0.1 \mathrm{mg} / \mathrm{kg}$, and fentanyl $2 \mathrm{mcg} / \mathrm{kg}$. Intubation was done after 3 mins with appropriate size cuffed endotracheal tube. Maintenance of anaesthesia was done by nitrous oxide (66\%) and oxygen (33\%) and intermittent halothane $0.5-1 \%$ and intermittent injection of vecuronium. Reversal of neuromuscular blockade was achieved with intravenous neostigmine and glycopyrrolate as needed. Extubation was done when standard criteria for extubation were fulfilled.

After surgery, patients were shifted to recovery room where they remained for the next 24 hours. In spite of no problem in immediate recovery, the patients were sent to recovery room instead of general ward only to monitor them closely - mere a logistic issue. During their stay in the recovery room, patients received $1000 \mathrm{mg}$ of paracetamol 8 hourly. Episodes of pain were treated with intravenous fentanyl 25 mcg at 10 minutes interval until pain subsides or any complication started or maximum allowable dose (100 $\mathrm{mcg} / \mathrm{hr}$ ) exceeds. The observer visited the patient at 1,4 , and 24 hour postoperatively when the intensity of pain was assessed using VAS at rest and with movement [Coughing]. Levels of postoperative nausea, vomiting, and sedation were assessed using a 4-point verbal scale (None, mild, moderate, and severe). Occurrence of headache and lightheadedness were recorded during these 24 hours.

\section{Analysis of Data}

After completion of the study, data were unblinded for entry into Microsoft excel sheet. Then, it was imported into statistical software package SPSS12.0 for Windows. Demographic profiles, 24-hour postoperative fentanyl consumption among the three groups and mean VAS scores at different postoperative hours were analysed with one way ANOVA. Pearson Chi-square test was applied for categorical data like ASA status, sedation, PONV score, headache, and lightheadedness.

\section{RESULTS}

The study spanned from September 2008 to March 2009. A total of 100 patients were assessed for eligibility. Seventy five patients received study medication after randomisation. Twenty five patients were not included in this study on account of patient's refusal, history of chronic medication with NSAIDS and steroid, inability to cooperate, severe systemic disease. Eleven persons were considered dropouts after initial randomisation and therefore not subjected to statistical analysis [ 6 patients did not want to continue, data could not be retrieved completely in 3 patients, 1 had severe bleeding, 1 had allergic reaction to one of the study drugs]. Unfortunately, we could not pinpoint the specific drug for that adverse reaction. Therefore, data of remaining 64 patients were assessed for final analysis (Figure 1).

There were no significant differences among the groups in respect to patient's age, weight, ASA, physical status, and duration of surgery (Table 1). Mean fentanyl consumption in the first 24-hour postoperative period was reduced by about $33 \%$ in group B $(188.10 \pm 35.02 \mathrm{mcg})$ and group A 
$(192.86 \pm 32.73 \mathrm{mcg})$ as compared to group C $(284.09 \pm 67.94$ mcg), $\mathrm{P}<0.001$ (tested with ANOVA).

The VAS score for pain at rest (Figure 2) and with movement (Figure 3) was significantly less in group A and group $\mathrm{B}$ as compared to group $\mathrm{C}(\mathrm{P}<0.001$; tested with ANOVA). Numbers of patients having adequate pain control at different postoperative time points are shown in Table 2 . There was no significant difference among the groups in respect to incidence of PONV; $\mathrm{P}=0.07$ (Table 3). Sedation was significantly more in group A and group $B$ than group $C, P$ value $=0.02$ (Table 4). There was no difference in occurrence of headache and light-headedness among all the groups.

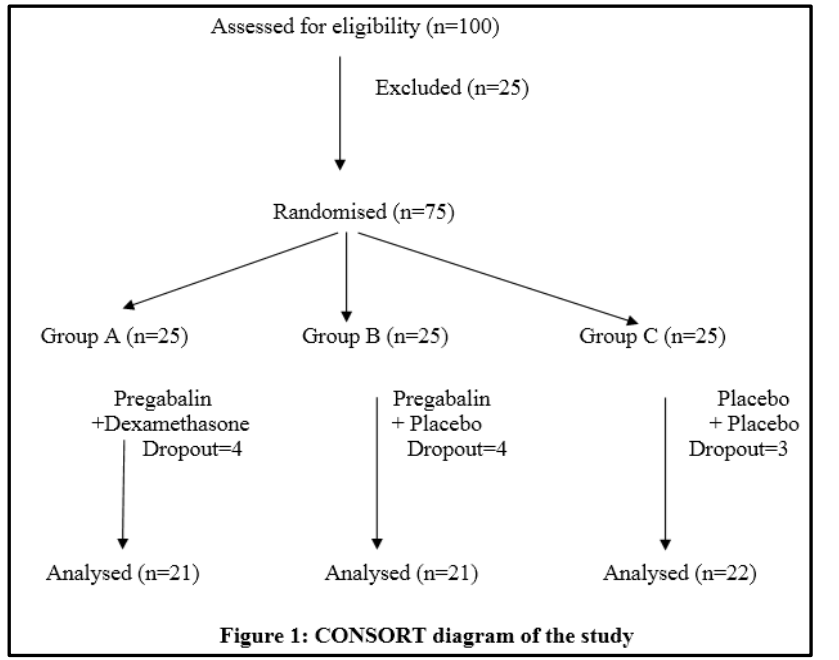

\begin{tabular}{|c|c|c|c|c|}
\hline Parameters & $\begin{array}{c}\text { Group A } \\
(\mathbf{n = 2 1 )}\end{array}$ & $\begin{array}{c}\text { Group B } \\
(\mathbf{n = 2 1 )}\end{array}$ & $\begin{array}{c}\text { Group C } \\
(\mathbf{n = 2 2})\end{array}$ & $\begin{array}{c}\text { P } \\
\text { value }\end{array}$ \\
\hline Age (yrs.) & $\begin{array}{c}55.05 \pm \\
8.49\end{array}$ & $\begin{array}{c}54.90 \pm \\
9.78\end{array}$ & $\begin{array}{c}54.86 \pm \\
10.89\end{array}$ & 0.998 \\
\hline Weight (kg) & $\begin{array}{c}58.90 \pm \\
8.87\end{array}$ & $\begin{array}{c}58.90 \pm \\
9.90\end{array}$ & $\begin{array}{c}58 \pm \\
8.37\end{array}$ & 0.931 \\
\hline Height (cm) & $\begin{array}{c}154.95 \pm \\
4.93\end{array}$ & $\begin{array}{c}153.86 \pm \\
6.74\end{array}$ & $\begin{array}{c}151.55 \pm \\
5.39\end{array}$ & 0.146 \\
\hline $\begin{array}{c}\text { ASA status } \\
\text { (I/II) }\end{array}$ & $11 / 10$ & $12 / 9$ & $14 / 8$ & 0.568 \\
\hline $\begin{array}{c}\text { Duration of } \\
\text { surgery(min) }\end{array}$ & $\begin{array}{c}100 \pm \\
15.57\end{array}$ & $\begin{array}{c}101.90 \pm \\
20.27\end{array}$ & $\begin{array}{c}102.05 \pm \\
21.53\end{array}$ & 0.929 \\
\hline $\begin{array}{c}\text { Data presented as mean } \pm \text { SD, and analysed using ANOVA } \\
\text { except that marked * which is categorical, and analysed }\end{array}$ \\
using Chi-square test. P< 0.05-Significant. \\
\hline \multicolumn{5}{|c|}{ and 1: Demographic Parameters } \\
\hline \multicolumn{5}{|c|}{ andion of Surgery } \\
\hline
\end{tabular}

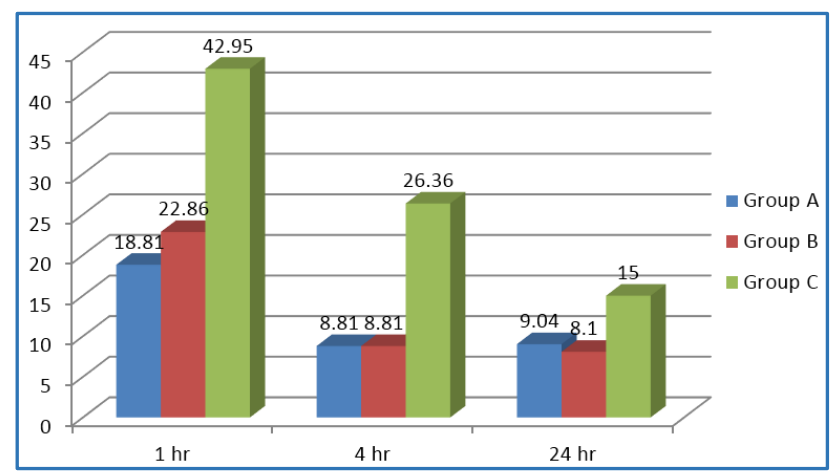

Fig. 2: Mean VAS Scores (in mm) at Rest at $1 \mathrm{hr}, 4 \mathrm{hr}$ and $24 \mathrm{hr}$ After Surgery

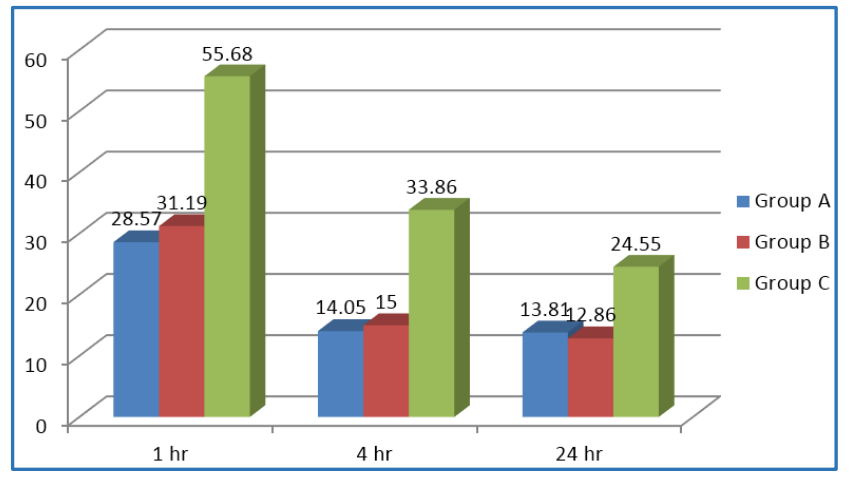

Fig. 3: Mean VAS Scores (in mm) at Movement at $1 \mathrm{hr}, 4 \mathrm{hr}$, and $24 \mathrm{hr}$ After Surgery

\begin{tabular}{|c|c|c|c|c|c|c|c|}
\hline \multirow[t]{2}{*}{ Parameters } & \multicolumn{2}{|c|}{$\begin{array}{c}\text { Group A } \\
(n=21)\end{array}$} & \multicolumn{2}{|c|}{$\begin{array}{c}\text { Group B } \\
(n=21)\end{array}$} & \multicolumn{2}{|c|}{$\begin{array}{c}\text { Group C } \\
(n=22)\end{array}$} & \multirow[t]{2}{*}{$\begin{array}{c}\mathbf{P} \\
\text { value }\end{array}$} \\
\hline & \begin{tabular}{|c|} 
VAS \\
Score \\
$\leq 30$ \\
\end{tabular} & \begin{tabular}{|c} 
VAS \\
Score \\
$>30$
\end{tabular} & $\begin{array}{c}\text { VAS } \\
\text { Score } \\
\leq 30 \\
\end{array}$ & \begin{tabular}{|c|} 
VAS \\
Score \\
$>30$ \\
\end{tabular} & \begin{tabular}{|c|} 
VAS \\
Score \\
$\leq 30$
\end{tabular} & \begin{tabular}{|c|} 
VAS \\
Score \\
$>30$ \\
\end{tabular} & \\
\hline $\begin{array}{c}\text { VAS_ } \\
\text { Rest_1 hr }\end{array}$ & 20 & 1 & 17 & 4 & 2 & 20 & $<0.001$ \\
\hline $\begin{array}{c}\text { VAS_ } \\
\text { Rest_4 hr }\end{array}$ & 21 & 0 & 21 & 0 & 18 & 4 & $<0.001$ \\
\hline $\begin{array}{c}\text { VAS } \\
\text { Rest_24 hr }\end{array}$ & 21 & 0 & 21 & 0 & 22 & 0 & $=0.001$ \\
\hline $\begin{array}{c}\text { VAS } \\
\text { Move_1 hr }\end{array}$ & 15 & 6 & 13 & 8 & 0 & 22 & $<0.001$ \\
\hline $\begin{array}{c}\text { VAS } \\
\text { Move_4 hr }\end{array}$ & 21 & 0 & 21 & 0 & 8 & 14 & $<0.001$ \\
\hline $\begin{array}{c}\text { VAS_Move } \\
24 \mathrm{hr}\end{array}$ & 21 & 0 & 21 & 0 & 20 & 2 & $<0.001$ \\
\hline $\begin{array}{r}\text { Data express } \\
\mathrm{P}<0.05-\end{array}$ & ced as & imbe & of $n$ & ants 8 & Di-cs & re te & $\begin{array}{l}\text { t done. } \\
\text { er. }\end{array}$ \\
\hline
\end{tabular}

\begin{tabular}{|c|c|c|c|}
\hline $\begin{array}{c}\text { Degree of } \\
\text { PONV }\end{array}$ & $\begin{array}{c}\text { Group A } \\
\text { (n=21) }\end{array}$ & $\begin{array}{c}\text { Group B } \\
\text { (n=21) }\end{array}$ & $\begin{array}{c}\text { Group C } \\
\text { (n=22) }\end{array}$ \\
\hline None & $15(71.42 \%)$ & $\begin{array}{c}10 \\
(47.61 \%)\end{array}$ & $9(40.9 \%)$ \\
\hline Mild & $5(23.83 \%)$ & $8(38.08 \%)$ & $4(18.18 \%)$ \\
\hline Moderate & $1(4.76 \%)$ & $2(9.52 \%)$ & $5(22.72 \%)$ \\
\hline Severe & 0 & $1(4.76 \%)$ & $4(18.18 \%)$ \\
\hline Data is presented as number of patients (\%). Categorical \\
data. Analysed with Chi-square test. P=0.07 \\
[P value<0.05 is significant]. \\
\hline \multicolumn{4}{|c|}{$\begin{array}{c}\text { Nable 3: Incidence of Postoperative } \\
\text { Nausea and Vomiting }\end{array}$} \\
\hline
\end{tabular}

\begin{tabular}{|c|c|c|c|}
\hline $\begin{array}{c}\text { Degree of } \\
\text { Sedation }\end{array}$ & $\begin{array}{c}\text { Group A } \\
(\mathbf{n = 2 1 )}\end{array}$ & $\begin{array}{c}\text { Group B } \\
\text { (n=21) }\end{array}$ & $\begin{array}{c}\text { Group C } \\
\text { (n=22) }\end{array}$ \\
\hline None & $3(14.28 \%)$ & $4(19.04 \%)$ & $13(59.09 \%)$ \\
\hline Mild & $6(28.57 \%)$ & $6(28.57 \%)$ & $5(22.72 \%)$ \\
\hline Moderate & $12(51.14 \%)$ & $10(47.61 \%)$ & $4(18.18 \%)$ \\
\hline Severe & 0 & $1(4.76 \%)$ & 0 \\
\hline \multicolumn{4}{|c|}{ Data is presented as number of patients (\%). } \\
Categorical data. Analysed with Chi-square test. \\
P= 0.02; [P value<0.05 is significant]. \\
\hline \multicolumn{4}{|c|}{ Table 4: Occurrence of Sedation Among Groups } \\
\hline
\end{tabular}

\section{DISCUSSION}

The present study demonstrated about 33\% reduction in fentanyl consumption in the first 24 hour postoperative period 
with the use of a single dose of $300 \mathrm{mg}$ pregabalin given preoperatively. Significant reduction of pain scores were noted at $1^{\text {st }}$ hour, at $4^{\text {th }}$ hour, and at $24^{\text {th }}$ hours in patients receiving both pregabalin and dexamethasone or pregabalin alone. It translates into better pain relief in the $1^{\text {st }} 24$ hours of postoperative period receiving pregabalin plus dexamethasone or pregabalin alone. Adequate pain control (VAS score $\leq 30$ in $\mathrm{mm}$ scale) was achieved in most of the patients of group A and group B at all the postoperative time points both at rest and with movement (Table 2). Although, patients of group $\mathrm{C}$ did not have adequate pain control initially at $1^{\text {st }}$ and $4^{\text {th }}$ postoperative hours. They achieved satisfactory pain control at $24^{\text {th }}$ postoperative hours probably at the cost of higher opioid consumption. Incidence of postoperative nausea vomiting was better controlled with the addition of $8 \mathrm{mg}$ of dexamethasone to pregabalin, although it was not significant when analysed. Sedation remained the most significant adverse effect among patients receiving pregabalin.

Pain after abdominal hysterectomy has both somatic and visceral component. Pregabalin has been suggested to reduce somatic element of pain more than visceral component. So, the pain and hyperalgesia in the incision area is reduced to a greater proportion than referred pain of hysterectomy. ${ }^{6}$ Hyperalgesia, which is the main contributor for establishment of chronic pain after surgery is proportional to the amount of tissue injury (Nerve damage leading to neuropathic pain) thus vary according to surgical technique (Laparoscopic procedure being less injurious than open procedure). It also depends on the quality of immediate postoperative pain control because the establishment of hyperalgesia occurs mostly during the first 24 hour following surgery. Opioids itself has been implicated for producing hyperalgesia. ${ }^{7}$ So, multimodal approach for pain control with antihyperalgesic like gabapentinoids and opioid-sparing drugs like paracetamol and steroids can be a valuable adjunct to the traditional opioid therapy.

Central pain sensitization plays an important role not only in chronic pain state, but also in postoperative pain and antihyperalgesic drugs blocks pathological pain while leaving physiological pain (With its protective function) intact.8,9 Pregabalin, a novel GABA analogue acts by binding with the alpha (2) delta $[\alpha 2 \delta$ ] subunits of the presynaptic voltagegated calcium channels at nerve terminals thereby reduces release of several excitatory neurotransmitters including glutamate, noradrenaline, serotonin, dopamine, substance $\mathrm{P}$ and CGRP; producing blockage of nociception-induced hypersensitization process in the central nervous system. Pregabalin works by slowing down impulses in the brain that cause seizures. Pregabalin also affects chemicals in the brain that send pain signals across the nervous system (Secondary effect). Hence, pregabalin has become a useful adjunct in the multimodal management of postoperative pain. Also, it plays an important role as preventive or protective analgesia by minimizing the incidences of chronic postsurgical pain syndrome when administered as oral pre-emptive analgesic for postoperative pain relief. ${ }^{10}$

Pregabalin is better than its congener gabapentin in terms of increased potency, better oral bioavailability (90\%), quicker onset of action ( 1 hour), and less side effects. ${ }^{3}$ It has also got anxiolytic property. ${ }^{11,12}$ Pregabalin has been recommended in a dose $75 \mathrm{mg}$ to $600 \mathrm{mg} /$ day for treatment of epilepsy and central neuropathic pain. It has linear pharmacokinetic profile across the therapeutic range with fewer side effects, most common being dizziness and somnolence, having no effect on arterial pressure or heart rate. Absolute contraindications for its use are those suffering from depression and/or having suicidal tendencies. ${ }^{13}$

After oral administration, the peak plasma concentration is achieved in 1 hour. 3 The dose used in the study is $300 \mathrm{mg}$ (single dose) as it is found to be optimal for postoperative pain control after hip arthroplasty 5 and dental surgery. ${ }^{14}$

Dexamethasone, a synthetic steroid, is well known for its anti-inflammatory and antiemetic action. Compared to other synthetic steroid, it is more potent with least mineralocorticoid action consequently least chances of sodium and water retention in the immediate postoperative period. The analgesic effect of glucocorticoid is provided through inhibition of phospholipase enzyme thereby blocking the Cyclooxygenase and the lipoxygenase pathway in inflammatory chain reaction. It also suppresses the tissue level of bradykinin and release of neuropeptide from free nerve endings. Single preoperative dose of $8 \mathrm{mg}$ of dexamethasone has been found to reduce postoperative pain, fatigue, after laparoscopic cholecystectomy. ${ }^{15}$ The combination of gabapentin with dexamethasone $8 \mathrm{mg}$ has also been found to improve postoperative analgesia and prevent PONV. ${ }^{16}$ Female patients, usually non-smoker, undergoing hysterectomy under general anaesthesia with opioid analgesic are at high risk for development of PONV and prophylactic dexamethasone has got definite role in reducing its incidence.

Nonsteroidal anti-inflammatory drugs are an integral part of multimodal analgesia. They have been found to act synergistically with gabapentin and pregabalin. ${ }^{17}$ Among the Cyclooxygenase inhibitors, paracetamol has fewer contraindications and it is relatively free from common side effects of NSAIDs involving gastrointestinal and renal systems. The dose used in this study was $1000 \mathrm{mg}$ thrice daily. Paracetamol inhibits only the Cyclooxygenase enzyme whereas dexamethasone inhibits both the phospholipase and Cyclooxygenase enzymes. Both have ceiling effect of analgesia not being effective as monotherapy. Hence, dexamethasone has been added to paracetamol to achieve synergism as suggested in Hval et al. ${ }^{4}$

The present study failed to demonstrate any additional benefit of adding dexamethasone to pregabalin in respect to postoperative pain score or opioid consumption. The pain scores were collected at 1,4 , and 24 hour after surgery. So, we could not comment from this study whether it has any analgesic effects beyond this period as has been found in the study of Hval et al. ${ }^{4}$ where $16 \mathrm{mg}$ of single-dose dexamethasone provided prolonged postoperative analgesia from 24 to 72 hours after breast surgery. More frequent and prolonged assessment would have demonstrated additional data in favour of dexamethasone. Moreover, the dose of dexamethasone used in this study ( $8 \mathrm{mg}$ ) is clearly low as compared to $16 \mathrm{mg}^{4}$ and $15 \mathrm{mg}^{18}$ used in other studies. Again, at low pain score (VAS $<3 \mathrm{~cm}$ ) most of the time patient might not have been able to appreciate any difference in pain with the addition of dexamethasone due to lack of sensitivity.

In the present study, use of pregabalin has been found to reduce the opioid requirement by $33 \%$ along with reduction of postoperative pain scores. Although, Mathiesen et al. 5 found a $50 \%$ reduction in postoperative opioid requirement. No difference in postoperative pain scores was observed with the 
addition of pregabalin. This may be due the difference in the postoperative rescue analgesic technique. The use of patient controlled analgesia resulted in low pain score (VAS $<3$ in $\mathrm{cm}$ scale) throughout at the cost of higher opioid consumption in that study. In contrast, administration of rescue analgesics as 'on demand supply' in our study may not be that much effective in reducing postoperative pain in the control group.

The incidence of PONV was quite common. Addition of dexamethasone caused a reduction in its incidence. Sedation scores were high among patient receiving pregabalin. It corroborates with the fact that sedation is a common side effect of gabapentinoids. Addition of dexamethasone did not have any effect on the sedation score as opposed to the results of the study of Mathiesen et al. ${ }^{5}$, which demonstrated significant reduction in postoperative sedation. It may be because of the high incidence of sedation of moderate degree in the present study as compared to mild sedation observed in that study. Dexamethasone may be able to act on mild sedation only improving the postoperative fatigue.

\section{CONCLUSION}

Preoperative administration of $300 \mathrm{mg}$ pregabalin was effective in reducing postoperative pain and opioid consumption. Addition of single dose injection of $8 \mathrm{mg}$ dexamethasone has no added advantage on postoperative pain control except some alleviation of postoperative nausea and vomiting.

\section{REFERENCES}

1. Kehlet H, Holte K. Effect of postoperative pain on surgical outcome. Br J Anaesth 2001;87(1):62-72.

2. Kehlet H, Dahl JB. The value of multimodal or balanced analgesia in postoperative pain treatment. Anaesth Analg 1993;77(5):1048-56.

3. Gajraj NM. Pregabalin: its pharmacology and use in pain management. Anaesth Analg 2007;105(6):1805-15.

4. Hval K, Thagaard KS, Schlichting E, et al. The postoperative analgesic effect when dexamethasone is added to a nonsteroidal anti-inflammatory drug (rofecoxib) before breast surgery. Anaesth Analg 2007; 105(2):481-6.

5. Mathiesen O, Jacobsen LS, Holm HE, et al. Pregabalin and dexamethasone for postoperative pain control: a randomized controlled study in hip arthroplasty. $\mathrm{Br} \mathrm{J}$ Anaesth 2008;101(4):535-41.

6. Mathiesen O, Rasmussen ML, Dierking G, et al. Pregabalin and dexamethasone in combination with paracetamol for postoperative pain control after abdominal hysterectomy a randomized clinical trial. Acta Anaesthesiol Scand 2009;53(2):227-35.
7. Kehlet H. Postoperative opioid sparing to hasten recovery: what are the issues? Anaesthesiology 2005;102(6):1083-5.

8. Dhal JB, Mathiesen O, Møiniche S. Protective premedication: an option with gabapentin and related drugs? a review of gabapentin and pregabalin in the treatment of post-operative pain. Acta Anaesthesiol Scand 2004;48(9):1130-6.

9. Dirks J, Fredensborg BB, Christensen D, et al. A randomized study of the effect of single dose gabapentin versus placebo on postoperative pain and morphine consumption after mastectomy. Anaesthesiology 2002;97(3):560-4.

10. Kolarkar P, Badwaik G, Kalbande J, et al. Efficacy of pregabalin in immediate post-operative pain control. Journal of Evidence based Medicine and Healthcare 2014;1(9):1141-9.

11. Lauria- Horner BA, Pohl RB. Pregabalin: a new anxiolytic. Expert Opin Investig Drugs 2003;12(4):663-72.

12. Baidya DK, Agarwal A, Khanna P, et al. Pregabalin in acute and chronic pain. J Anaesth Clin Pharmacol 2011;27 (3): 307-14.

13. Elstraete VAC, Tirault M, Lebrun $\mathrm{T}$, et al. The median effective dose of pre-emptive gabapentin on postoperative morphine consumption after posterior lumbar spinal fusion. Anaesth Analg 2008;106(1):305-8.

14. Hill CM, Balkenohl M, Thomas DW, et al. Pregabalin in patients with postoperative dental pain. Eur J Pain 2001;5(2):119-24.

15. Bisgaard $\mathrm{T}$, Klarskov B, Kehlet $\mathrm{H}$, et al. Preoperative dexamethasone improves surgical outcome after laparoscopic cholecystectomy: a randomized double blind placebo controlled trial. Ann Surg 2003;238(5): 651-60.

16. Koc $S$, Memis D, Sut N. The preoperative use of gabapentin dexamethasone and their combination in varicocele surgery: a randomized controlled trial. Anaesth Analg 2007;105(4):1137-42.

17. Hurley RW, Chatterjea D, Feng RM, et al. Gabapentin and pregabalin can interact synergistically with naproxen to produce antihyperalgesia. Anaesthesiology 2002;97 (5): 1263-73.

18. Jokela RM, Ahonen JV, Tallgren MK, et al. The effective analgesic dose of dexamethasone after laparoscopic hysterectomy. Anaesth Analg 2009;109(2):607-15. 